\title{
Endsystolic versus enddiastolic scar imaging for transmurality assessment
}

\author{
Andreas Schuster , Amedeo Chiribiri, Geraint Morton, Masaki Ishida, Kalpa De Silva, Matthias Paul, Shazia Hussain, \\ Divaka Perera, Eike Nagel
}

From 2011 SCMR/Euro CMR Joint Scientific Sessions

Nice, France. 3-6 February 2011

\section{Objective}

To investigate the influence of endsystolic scar imaging over routine enddiastolic scar imaging on transmurality.

\section{Background}

The late gadolinium enhancement (LGE) technique has been an important achievement in cardiovascular magnetic resonance (CMR) and is widely used to precisely localize and determine the amount of necrosis and fibrosis. The percentage of transmurality of LGE is inversely related to the likelihood of functional recovery after revascularisation. LGE imaging is usually performed in enddiastole as recommended by current guidelines of the SCMR. Whether or not endsystolic imaging would significantly influence transmurality in patients with ischemic scarring remains unclear.

\section{Methods}

107 segments with moderate hypokinesia or more severe wall motion abnormalities were studied in 20 patients with established coronary artery disease referred for viability assessment (33\% of all segments). We used a SSFP standard 4-chamber view to determine the endsystolic and enddiastolic position in the cardiac cycle. LGE imaging was performed with patient specific trigger delays to obtain enddiastolic $\left(\mathrm{LGE}_{\mathrm{ed}}\right)$ and endsystolic $\left(\mathrm{LGE}_{\mathrm{es}}\right)$ images. Enddiastolic and endsystolic wall thickness $\left(\mathrm{WT}_{\mathrm{ed}}\right.$ and $\mathrm{WT}_{\mathrm{es}}$ ), thickness of the remaining viable rim $\left(\mathrm{RIM}_{\mathrm{ed}}\right.$ and $\left.\mathrm{RIM}_{\mathrm{es}}\right)$ and thickness of scar in enddiastole was measured manually.

\section{Results}

Evidence of LGE was $84 \%$ in all dysfunctional segments with a mean scar of $3.4 \pm 2.5 \mathrm{~mm}$. Total wall thickness and the thickness of the remaining viable myocardium increased from diastole to systole $\left(\mathrm{WT}_{\text {ed }} 7.9 \pm 1.9\right.$ versus $\mathrm{WT}_{\text {es }} 8.4 \pm 2.2, \mathrm{p}<0.001 ; \mathrm{RIM}_{\text {ed }} 4.5 \pm 3.1$ versus $\mathrm{RIM}_{\text {es }} 5$ $\pm 3.4, \mathrm{p}<0.001)$. There was a difference between the transmurality of scar measured in enddiastole and endsystole $\left(\mathrm{LGE}_{\mathrm{ed}} 46 \pm 33 \%\right.$ versus $\mathrm{LGE}_{\mathrm{es}} 44 \pm 33 \%, \mathrm{p}<0.001$ ). This difference was most pronounced in a subgroup of segments $(n=50)$ between 25 and $75 \%$ transmurality of LGE $\left(\mathrm{LGE}_{\text {ed }} 57 \pm 18 \%\right.$ versus $\mathrm{LGE}_{\mathrm{es}} 53 \pm 18 \%$, p $\left.<0.001\right)$. Reduced transmurality was inversely correlated with increased thickness of the remaining viable rim between diastole and systole $(r=-0.73)$.

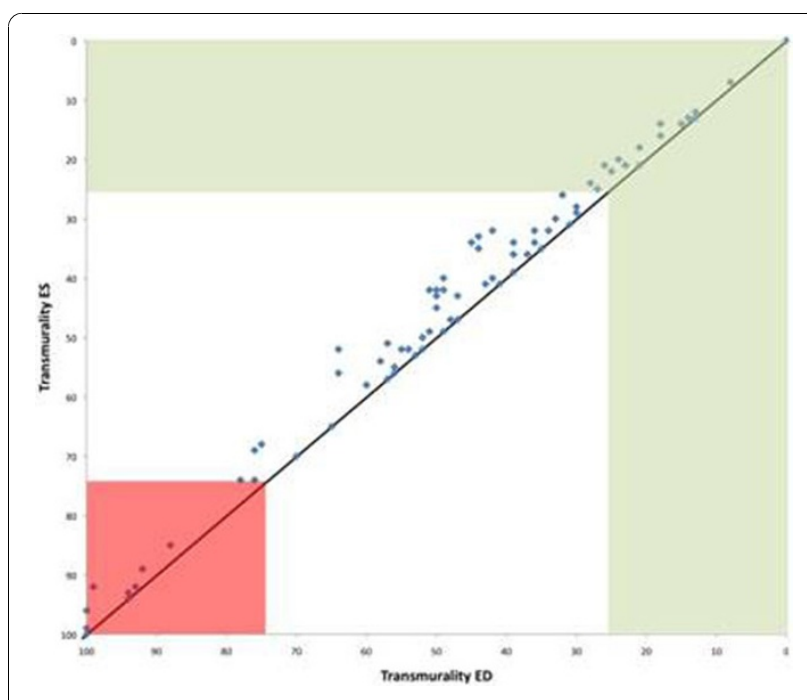

Figure 1 Differences between transmurality in enddiastole and endsystole. Red area indicates transmurality above $75 \%$ and green area below 25\%. 


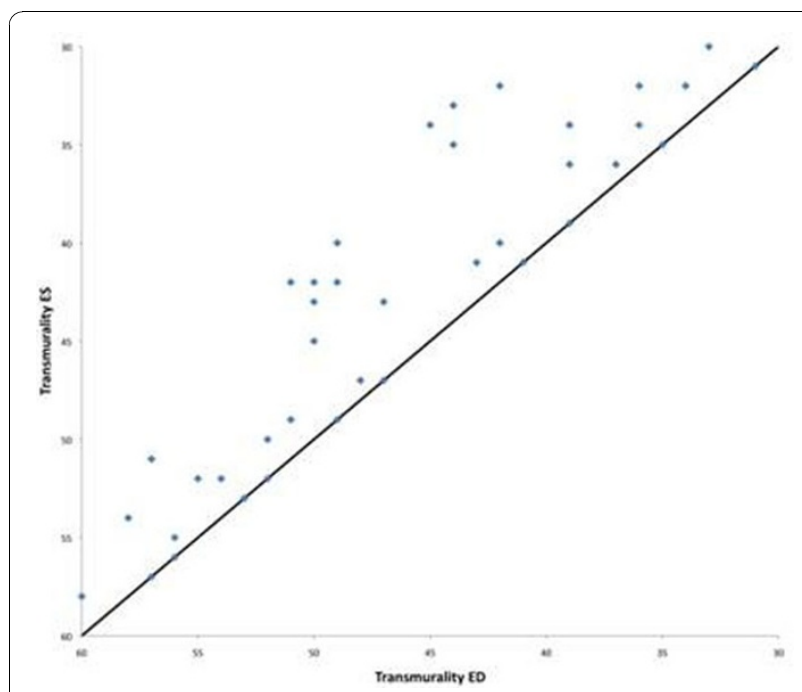

Figure 2 Differences between transmurality in enddiastole and endsystole. Especially in segments with intermediate transmurality this difference can be more extensive.

\section{Table 1}

\begin{tabular}{|c|c|}
\hline $\begin{array}{l}\text { Enddiastolic versus endsystolic LGE imaging and } \\
\text { segmental transmurality }\end{array}$ & $\mathrm{p}$ \\
\hline \multicolumn{2}{|l|}{ All segments $(n=107)$} \\
\hline $\mathrm{LGE}_{\mathrm{ed}} 46 \pm 33 \%$ versus $\mathrm{LGE}_{\mathrm{es}} 44 \pm 33 \%$, & $<0.001$ \\
\hline \multicolumn{2}{|l|}{ Segments with up to $25 \%$ transmurality $(n=25)$} \\
\hline $\mathrm{LGE}_{\mathrm{ed}} 25 \pm 9 \%$ versus $\mathrm{LGE}_{\mathrm{es}} 22 \pm 8 \%$ & $<0.001$ \\
\hline \multicolumn{2}{|l|}{ Segments with $25 \%$ and $75 \%$ transmurality $(n=50)$} \\
\hline $\mathrm{LGE}_{\mathrm{ed}} 57 \pm 18 \%$ versus $\mathrm{LGE}_{\mathrm{es}} 53 \pm 18 \%$ & $<0.001$ \\
\hline \multicolumn{2}{|l|}{ Segments with transmural scar $(n=15)$} \\
\hline $\mathrm{LGE}_{\mathrm{ed}} 99 \pm 1 \%$ versus $\mathrm{LGE}_{\mathrm{es}} 99 \pm 2 \%$ & 0.55 \\
\hline
\end{tabular}

\section{Conclusion}

Transmurality of scar changes little with varying acquisition times in the cardiac cycle. However there is a statistically significant difference between transmuralities derived from enddiastolic and endsystolic LGE imaging mainly due to the function of the remaining viable rim. Clinically this might not impact on decision making but clearly shows the importance of standardized imaging protocols especially in research studies.

Published: 2 February 2011

doi:10.1186/1532-429X-13-S1-P158

Cite this article as: Schuster et al.: Endsystolic versus enddiastolic scar imaging for transmurality assessment. Journal of Cardiovascular Magnetic Resonance 2011 13(Suppl 1):P158.

\section{Submit your next manuscript to BioMed Central} and take full advantage of:

- Convenient online submission

- Thorough peer review

- No space constraints or color figure charges

- Immediate publication on acceptance

- Inclusion in PubMed, CAS, Scopus and Google Scholar

- Research which is freely available for redistribution 